\title{
Perceived structure of abstract paintings as a function of structure of music listened to on initial viewing
}

\author{
DANIEL LINDNER and MICHAEL T. HYNAN \\ University of Wisconsin-Milwaukee, Milwaukee, Wisconsin
}

\begin{abstract}
Marks (1978) described a sensory unity theory that postulated that common dimensions of experience exist across sensory modalities, allowing each modality to affect the others. We examined whether structural judgments of visual stimuli made by male and female subjects would be influenced by exposure to auditory stimuli. Twenty-eight subjects saw a sequence of identical slides of abstract paintings. One group listened to avant-garde music while viewing the slides; the other group listened to minimalistic music. Afterward, subjects rated each of the paintings on semantic-differential scales. We hypothesized that the subjects would rate the paintings according to the structural qualities of the music they had heard. Significant effects of music condition supported hypotheses for the evaluation and activity dimensions only. Also, a significant interaction between sex and music condition was found for the potency dimension, with females rating the paintings more like the music they had listened to and males showing the opposite tendency. We interpreted the interaction in terms of emotional differences between the sexes. It was postulated that cross-modal diffusion may affect both cognitive and emotional processes.
\end{abstract}

Although paintings are perceived by the sense of sight and music is perceived by the sense of hearing, a number of studies have suggested common dimensions of experience between these two media. Cowles (1935) found a high degree of agreement between ratings of the mood of a musical selection and ratings of paintings chosen to represent the selection. Simon and Wohlwill (1968) also found agreement between choice of visual patterns and musical selections chosen to represent the patterns. Also, Wehner (1966) has shown that subjects are able to match paintings by Paul Klee with the music that inspired Klee to create them.

Thus, music and visual art may be experienced along common dimensions, which are, in a strict sense, reserved for only one modality. For example, certain paintings and music may both be described as loud and rhythmic, terms generally limited to auditory experience, or as bright and circular, terms generally limited to vision.

One way of explaining the use of the same descriptive terms across different sensory modalities is Marks's (1978) theory of sensory unity. Marks stated that the senses are not independent processes, but are closely related because common dimensions of experience exist across modalities. Common descriptive terms can thus be used interchangeably across the senses to describe experience. Marks elaborated on the idea of a synesthetic capacity within perception as being the ability to recognize and appreciate the many experiential similarities across the senses. One does not only think in a synesthetic

The second author's mailing address is: Department of Psychology, The University of Wisconsin-Milwaukee, P.O. Box 413, Milwaukee, WI 53201. manner in this model; one also receives perceptual information in a synesthetic fashion. According to Marks, interactions between the modalities are always taking place, each affecting and being affected by the others.

Although the findings of Cowles (1935), Simon and Wohlwill (1968), and Wehner (1966) match this theoretical framework in that common moods, concepts, and perceptions are found in both music and painting, actual effects of one medium of art on another have not been extensively studied. One exception is Parrott (1982), who examined the effects of paintings and music (both alone and together) on emotional judgments. Parrott found that the effects of music and paintings were essentially additive. However, the effects of music on emotional judgments of paintings were minimal, whereas judgments about music were more affected by the presence of paintings.

The present study addressed the question of whether the perceived structural aspects of paintings could be affected by manipulating the structural qualities of music listened to while initially viewing the paintings. In addition, sex differences were investigated.

Since a certain degree of ambiguity was desired for the visual material, abstract paintings were used. Two groups of subjects were shown slides of eight abstract paintings. One group listened to highly unstructured avant-garde music while viewing; the other group listened to highly structured minimalistic music. Afterward, subjects rated each painting, using semantic-differential scales, without listening to music. We hypothesized that the subjects would judge the paintings to be structurally similar to the music they heard. 


\section{METHOD}

\section{Subjects}

Subjects were 14 males and 14 females of college age. Subjects were naive regarding the hypotheses of the experiment.

\section{Materials}

Eight abstract paintings were used in the study: J. Bazaine's "Traversee de l'aube," H. Hoffman's "The Gate,' V. Kandinsky's "White Line No. 232," E. Matta's "Disasters of Mysticism," J. Miro's "Blue II," P. Mondrian's "Composition in Color A" and "Flowering Trees," and A. O. W. Schulze's "Blue Composition." A Kodak Carousel was used to project color slides of each painting.

The semantic-differential ratings (Osgood, Suci, \& Tannenbaum, 1967) consisted of nine word-pairs, with three pairs for each dimension of evaluation, potency, and activity. Each word pair was rated on a 7-point scale. The items for the evaluation dimension were controlled-accidental, ordered-chaotic, and unified-fragmented; the items for the potency dimension were constrained-free, rigid-flexible, and constricted-expanded; and the items for the activity dimension were repetitive-varied, peaceful-tense, and stable-unstable. The first word of each word pair was assumed to describe qualities of minimalistic music, and the second word of each pair was assumed to describe qualities of avant-garde music.

Avant-garde music consisted of the first 8 min of Bulent Arel's "Stereo Electronic Music \#1." Minimalistic music consisted of the first 8 min of Phillip Glass's “Contrary Motion." Both selections were played in stereo using a cassette deck.

\section{Procedure}

Subjects were assigned to either the minimalistic or avant-garde group, with the restriction that equal numbers of each sex were represented in each group. The experimenter instructed each subject that attentional processes would be tested and gave each subject an envelope to be opened after the slide-and-music presentation. The slides were then shown with the appropriate music for $8 \mathrm{~min}$, with each slide appearing twice for $30 \mathrm{sec}$. After this presentation, each subject turned on a desk lamp and read the instructions in the envelope. The instructions informed subjects how to use the rating scales to rate the slides which would be shown again. Each of the eight slides was then shown for $1 \mathrm{~min}$ with no background music. Each slide was rated on each of the nine items.

\section{RESULTS}

Each of the three dimensions of the semantic differential was analyzed separately using 2 (music condition) $\times 2$ (sex of subject) analyses of variance. In each analysis, the dependent measure was the average rating for the three word pairs collapsed across ratings for the eight paintings.

The main effect of music on evaluative ratings was significant $[F(1,24)=4.4, p<.05]$. Subjects hearing minimalistic music later rated the paintings as controlled, ordered, and unified. Subjects hearing avant-garde music rated the paintings as accidental, chaotic, and fragmented. The main effect of music on activity ratings was also significant $[F(1,24)=16.0, p<.01]$. Subjects hearing minimalistic music later rated the paintings as repetitive, peaceful, and stable. Subjects hearing avant-garde music rated the paintings as varied, tense, and unstable. There were no main effects of sex and no interactions in the analyses of evaluation and activity ratings.

There were no significant main effects in the analysis of potency ratings. There was, however, a significant interaction of sex $\times$ music type $[F(1,24)=8.5, p<.01]$. Females hearing minimalistic music rated the paintings as constrained, rigid, and constricted, whereas females hearing avant-garde music rated the paintings as free, flexible, and expanded $[F(1,12)=6.3, p<.05]$. Male subjects gave potency ratings that were opposite in pattern to those given by the female subjects $[F(1,12)=5.2$, $p<.05]$.

\section{DISCUSSION}

Results for the evaluation and activity dimensions indicate support for the hypothesis that structural ratings of the abstract paintings were in the same direction as the actual structural qualities specific to the music previously heard. Subjects who listened to the minimalistic music later judged the paintings to be less accidental, unstable, and so forth than did those subjects who had listened to avant-garde music; the latter group judged the paintings to be more accidental, unstable, and so forth. Thus, it seems that complex auditory and visual materials experienced in conjunction integrate in a manner such that the structural qualities of auditory stimuli influence the perception of structural qualities of visual stimuli for the dimensions of evaluation and activity.

The interaction of subject sex with music condition raises an interesting issue for interpretation. Females rated the paintings on the potency dimension in the direction of the qualities of the music they had listened to, whereas males rated the paintings on that dimension in the direction opposite to that of the music they had heard. A possible explanation for these results may be based on Leventhal and Cupchik's (1976) study in which females were found to be better at self-referencing their emotions than were males. Females in that study integrated their emotions into their responses, whereas males tended to objectify the situation and respond the opposite of what they actually felt.

Given this difference, one can also assume that one or more dimensions of semantic space may have a stronger relationship to emotional reactions than do others (Osgood et al., 1967). In the present study, judgments of evaluation and activity may have referred more to those simple external qualities of the stimuli that did not require introspection for judgment. Thus, for evaluation and activity dimensions, the qualities of the visual perception were encoded in the same direction as were the structural qualities of the music.

The potency dimension, however, may have required more introspection to determine the impact that the paintings had on oneself. Since males tend to objectify such judgments (Leventhal \& Cupchik, 1976), males may have responded in a pendulous manner, rating the paintings as having qualities opposite to those of the music. Because females are better able to integrate their congnitions and emotions, females treated the potency factor in the same manner as the other two dimensions, rating the paintings as having qualities similar to those of the music. Thus cross-modal diffusion may operate in such a way that the unity of the senses affects one's emotional as well as one's perceptual and cognitive processes.

\section{REFERENCES}

Cowles, J. T. (1935). An experimental study of the pairing of certain auditory and visual stimuli. Journal of Experimental Psychology, 18, 461-469.

Leventhal, H., Cupchik, G. A. (1976). A process model of human judgment. Journal of Communication, 26, 190-204.

Marks, L. E. (1978). The unity of the senses (1st ed.). New York: Academic Press.

Osgood, C. E., Suci, G. J., \& Tannenbaum, P. H. (1967). The measurement of meaning. Urbana, IL: University of Illinois Press.

PARRotr, A. C. (1982). Effects of paintings and music, both alone and 
in combination, on emotional judgments. Perceptual \& Motor Skills, $54,635-641$.

Simon, C. R., \& WoHLwill, J. F. (1968). The role of expectation and variation in music. The Journal of Research in Music Education, 16, 227-238.
WeHNeR, W. L. (1966). The relation between six paintings by Paul Klee and selected musical compositions. The Journal of Research in Music Education, 15, 220-224.

(Manuscript received for publication June 30, 1986.)

\section{NOTICE}

\section{Abstracts of All Psychonomic Society Journal Articles Published in the Bulletin of the Psychonomic Society}

With the March 1987 issue, the Bulletin of the Psychonomic Society will launch the publication of a section that will contain abstracts of all articles that have appeared in recent issues of the other five Psychonomic Society journals-Animal Learning \& Behavior; Behavior Research Methods, Instruments, \& Computers; Memory \& Cognition; Perception \& Psychophysics; and Psychobiology. It is hoped that this feature will provide readers with additional access to information that will be of use in their work. 